\title{
Phytochemical analysis and antioxidant assay of Melissa officinalis L. (lemon balm)
}

\author{
Lidia-Ioana Virchea ${ }^{*}$, Felicia Gabriela Gligor $^{1}$, Adina Frum $^{1}$, Monica Mironescu ${ }^{1}$, Nina I. \\ Myachikova $^{2}$, and Cecilia Georgescu ${ }^{1 *}$ \\ ${ }^{1}$ University "Lucian Blaga", 550024, Sibiu, Romania \\ ${ }^{2}$ Belgorod State National Research University, 308015, Belgorod, Russia
}

\begin{abstract}
Melissa officinalis L. called in popular language lemon balm is a medicinal plant belonging to the Lamiaceae family. The plant contains a variety of bioactive compounds among which volatile oils, flavonoids and phenolic acids. These are responsible for a lot of beneficial effects in disease relief. Lemon balm has antioxidant, antimicrobial, neuroprotective, anxiolytic, spasmolytic and other effects. Important for its antioxidant activity are flavonoids and phenolic acids which are well known for their ability to scavenge the free radicals. Due to this effect, lemon balm protects against the development of degenerative diseases such as Alzheimer's disease, cardiovascular disease, cancer and dermatological disorders. In this study we extracted and determined the content of the volatile oil and flavonoids from Melissa officinalis L. and we investigated the antioxidant activity of an extract obtained from dried aerial parts of lemon balm. The results showed that the volatile oil content was low $(0.17 \mathrm{~mL} / 100 \mathrm{~g}$ vegetal material). The total flavonoid content was $0.965 \mathrm{~g}$ rutoside/ $100 \mathrm{~g}$ of vegetal product and the antioxidant activity was $90.40 \%$. From this study, we concluded that Melissa officinalis L. is a potential source of antioxidant compounds with a lot of other benefits for human health.
\end{abstract}

Keywords: Melissa officinalis L., antioxidant assay, lemon balm.

\section{Introduction}

Melissa officinalis L. is a perennial edible medicinal plant belonging to the Lamiaceae family. It originated from southern Europe, Eastern Mediterranean region, Caucasus, northern Iran, Northern Africa and Western Asia [1-3]. Beside its scientific name, Melissa officinalis L. has also some common names: lemon balm, bee balm or honey balm [1]. The plant can reach a height of $30-125 \mathrm{~cm}$ and it is covered with short hairs. The stem of the plant is erect, with branches, it is quadrangular and frequently glabrous. The leaves are ovate in shape and they are petiolate. The flowers are white or light pink and they are grouped in clusters. The plant has small, dark brown or black seeds [4].

The chemical composition of Melissa officinalis L. consists of volatile oils, flavonoids, triterpenoids, phenolic acids [4], tannins, monoterpene glycosides, sesquiterpenes and triterpenes [1]. Volatile oils are mixtures of aromatic compounds with low molecular weight

\footnotetext{
*Corresponding author: lidia_virchea@yahoo.com, cecilia.georgescu@ulbsibiu.ro
} 
[5]. Essential oil of Melissa officinalis L. can be extracted by hydro-distillation and the chemical composition of the volatile oil can be analyzed by GC/MS (gas chromatography coupled with mass spectrometry) [6], GC-FID (gas chromatography coupled with an ionization flame detector) [3], HPLC (high performance liquid chromatography) or NMR (nuclear magnetic resonance [7]. The amount of volatile oil in vegetal raw material is about $0.1-0.5 \%$ of the plant weight [1]. Climatic factors, light, temperature, harvesting time influence the extraction yield and the composition of Melissa officinalis L. volatile oil. However, the main components of the Melissa officinalis L. volatile oil are geranial, neral, citronellal and geraniol. Other components identified in lemon balm volatile oil are methyl citronellate, ocimene, citronellol, nerol, $\beta$-caryophyllene, $\beta$-caryophyllene oxide and linalool [1]. Flavonoids are secondary metabolites of plants. From the structural point of view, flavonoids consist of a benzopyran heterocycle attached to a benzene ring [4]. The flavonoids identified in lemon balm are luteolin, luteolin 7-O-beta-D-glucopyranoside, apigenin 7-Obeta-D-glucopyranoside, and luteolin 3-O-beta-D-glucuronopyranoside [1]. Quercitrin, rhamnocitrin and luteolin are flavonoids identified in the leaves of lemon balm [8].

Medicinal properties of Melissa officinalis L. was mentioned for the first time by Discorides (40-90 AD) in his work De Materia Medica. This plant is included in some pharmacopoeias such as European Pharmacopoeia, British Herbal Pharmacopoeia and Iranian Herbal Pharmacopoeia [4]. Due to its complex composition, Melissa officinalis L. is traditionally used for the treatment of a variety of ailments. Some pharmacological effects of the plant have been shown by different studies. It has an antimicrobial (antibacterial, antifungal [3], antiviral [2]) effect. The lemon balm volatile oil is responsible for the antibacterial and antifungal effects. It is highly active against human and foodborne bacteria and fungi such as Staphylococcus aureus, Pseudomonas aeruginosa, Escherichia coli, Klebsiella pneumoniae, Salmonella enterica, Listeria monocytogenes and Candida albicans [3]. The volatile oil also possesses an antiviral effect on herpes virus (HSV-1) and HIV due to the presence of phenolic acids (caffeic, rosmarinic and ferulic acids) $[1,2,8]$. The antioxidant activity of Melissa officinalis L. is due to phenolic compounds and flavonoids [2]. It can reduce even natural and synthetic free radicals [1]. Free radicals in the human body can lead to various diseases such as cardiovascular diseases, cancer, skin [2] and Alzheimer disease. The mechanism of these diseases is correlated with free radicals that oxidize biomolecules such as DNA, proteins and lipids [7]. Antioxidants are a class of compounds that prevent oxidation induced by free radicals. Over time, synthetic antioxidants such as BHA (butylated hydroxyanisole) and BHT (butylated hydroxytoluene) have been used as antioxidants in food. These compounds have been shown to be toxic and carcinogenic, so the legislative restriction of them has increased interest in natural antioxidants. In addition to their use in foods, natural antioxidants are studied in terms of preventing cell damage induced by oxidative stress. An important source of natural antioxidants are medicinal plants which contain polyphenols [2]. The mechanism of antioxidant activity is related to the ability to chelate the iron (II), to reduce the DPPH [1], to scavenge the free radicals, to inhibit the production of reactive species that lead to lipid peroxidation and to rinse the plasma concentration of the enzymes involved in the body's defense against reactive oxygen species [8]. Many studies investigated the anxiolytic, antidepressant, antistress, anti-Alzheimer and neuroprotective effect of lemon balm [1]. Cases et al. showed that an extract from Melissa officinalis L. which contain rosmarinic, ursolic and oleanolic acids reduces stress and anxiety symptoms in humans [9]. The plant has the potential to improve mood, memory, cognition and concentration $[1,4]$. It has sedative and tranquilizing effects and it is used in the treatment of insomnia, epilepsy, psychosis and hysteria. Lemon balm protects against cardiovascular diseases, it has hypotensive properties and it is recommended in cardiac failure and arrhythmia. The lemon balm volatile oil is used in indigestion, flatulence, colic and nausea. 
It has antispasmodic and anti-inflammatory effects [1]. The volatile oil is also used in food and cosmetic industries. Due to its intense flavor, it is used to flavor dishes [1, 4].

The lemon balm herb is safe when used in correct doses (up to 30 days) topically or orally. It is not recommended in pregnancy, lactation, children and patients with thyroid disorders or in combination with sedatives $[1,8]$.

The aim of this study was to extract the volatile oil and flavonoid from Melissa officinalis L., to investigate the total flavonoid content and to test the antioxidant activity of an extract using DPPH scavenging assay.

\section{Material and methods}

\subsection{Plant material}

Melissae herba was collected during flowering from unpolluted areas from spontaneous flora of Rod village, Sibiu County, Romania. The plants were dried in a thin layer in shady and airy places. After drying the plants were stored in bags in cool places until using them in analysis.

\subsection{Volatile oil extraction}

The extraction of volatile oil was made according to the method presented in FRX, with some differences. Dried aerial parts of Melissa officinalis L. were subjected to steam distillation, for 5 hours in a neo-Clevenger apparatus modified by Moritz. $1 \mathrm{~mL}$ of benzene was added to the volatile oil obtained. Then the volatile oil was dried over anhydrous sodium sulfate in a glass vial, the benzene was evaporated and the volatile oil was stored refrigerated away from light and heat until analyzed $[6,10]$.

The yield of volatile oil from Melissa officinalis L. was calculated by the following formula (1):

$$
\eta=\frac{\text { volume of volatile oil in } m L}{\text { weight of dried vegetal material ing }} * 100
$$

\subsection{Total flavonoid content}

For the extraction of flavonoids, a method presented in Romanian Pharmacopoeia $\mathrm{X}^{\text {th }}$ Edition was used. This is a colorimetric method based on the reaction of flavonoids with aluminum chloride. $1 \mathrm{~g}$ of dried aerial parts of Melissa officinalis L. was mixed with $100 \mathrm{~mL}$ of ethanol $50 \%$. The mixture was heated to boiling in a water bath, at reflux for 30 minutes. The hot solution was filtered through cotton in a $100 \mathrm{~mL}$ volumetric flask. After cooling, it was completed with the same solvent by washing the residue until the solution reached the mark on the flask. $10 \mathrm{~mL}$ of that solution was diluted with methanol at $25 \mathrm{~mL}$ in a volumetric flask. After a period of 2-3 minutes of mixing, the solution was kept at rest for 10 minutes. Then the solution was filtered and the first part of the filtrate was removed. For sample preparation, $5 \mathrm{~mL}$ of filtrate was mixed with $5 \mathrm{~mL}$ of sodium acetate $100 \mathrm{~g} / \mathrm{L}$ and $3 \mathrm{~mL}$ of aluminum chloride $25 \mathrm{~g} / \mathrm{L}$ in a volumetric flask. After 15 minutes, the solution was made up to $25 \mathrm{~mL}$ with methanol if necessary. In parallel, an additional fluid consisting of $5 \mathrm{~mL}$ of filtrate, 8 $\mathrm{mL}$ of water and methanol up to $25 \mathrm{~mL}$ was prepared under the same conditions. The absorbance of the sample was determined at a wavelength of $430 \mathrm{~nm}$. 
The concentration of flavonoids in the sample was determined using a calibration curve. To obtain the calibration curve, four solutions of different concentrations were prepared from rutoside $0.1 \mathrm{~g} / \mathrm{l}$ in methanol standard solution, over which $5 \mathrm{~mL}$ of sodium acetate $100 \mathrm{~g} / \mathrm{L}$ and $3 \mathrm{~mL}$ of aluminum chloride $25 \mathrm{~g} / \mathrm{L}$ were added. Then the solutions was made up to 25 $\mathrm{mL}$ with methanol.

A solution obtained under the same conditions as the samples, consisting of $8 \mathrm{~mL}$ of water and up to $25 \mathrm{~mL}$ of methanol, was used as an additional fluid [10].

The concentration (mg rutoside/ $25 \mathrm{~mL}$ ) corresponding to the absorbance of the sample was calculated with the formula (2):

$$
X=\frac{A+0,11}{1.3} \quad \text { (2) }
$$

Where A is the absorbance of the sample solution.

The flavonoid content was calculated with the following formula (3):

$$
C_{g \%}=X * 5 \quad \text { (3) }
$$

Where $\mathrm{X}$ is the concentration corresponding to the absorbance of the sample.

\subsection{Antioxidant activity assay}

The antioxidant activity of a methanolic extract was tested by DPPH free radical scavenging method using a calibration curve. The extract was obtained through the method presented by Patel et al. [11] with some modifications. 0,5 g dried Melissa officinalis L. herba were mixed with $10 \mathrm{~mL}$ of solvent mixture consisting of methanol : water : hydrochloric acid $0,12 \mathrm{M}=$ $70: 29: 1(\mathrm{v} / \mathrm{v} / \mathrm{v})$ and it was left to stand at room temperature for 24 hours. Then, the mixture was placed in an ultrasonic bath (Bandelin Sonorex) at $25^{\circ} \mathrm{C}$ for 30 minutes. After 30 minutes, the mixture was subjected to centrifugation at $8000 \mathrm{rpm}$ for 10 minutes using an EBA 21 Hettich Centrifuge. The supernatant was collected and the residue was reextracted with $10 \mathrm{~mL}$ of solvent in an ultrasonic bath at $25^{\circ} \mathrm{C}$ for 15 minutes. The mixture was centrifuged again in the same conditions and the supernatant was collected. The total volume of supernatant was concentrated on a rotary evaporator. The residue was mixed with $10 \mathrm{~mL}$ of methanol, then it was filtered and made up to $10 \mathrm{~mL}$ using the same solvent.

To achieve the calibration curve, we followed the method described by Tylkowski et al. in a previous study. Briefly, we prepared a standard solution of DPPH $25 \mu \mathrm{g} / \mathrm{mL}$. Then, solutions with different concentrations of DPPH were prepared from the standard solution. The absorbance of these solutions were measured at $515 \mathrm{~nm}$.

The sample was prepared by mixing $970 \mu \mathrm{l}$ of DPPH $25 \mu \mathrm{g} / \mathrm{mL}$ standard solution with 30 $\mu \mathrm{l}$ of extract obtained through the method described above. The extinction of the sample was measured with a CECIL 1021 spectrophotometer at $515 \mathrm{~nm}$ [12].

The formula (4) for calculating the DPPH concentration is given below:

$$
C_{D P P H}=\frac{E-c . i .}{c . s .} \quad \text { (4) }
$$

Where:

$\mathrm{C}_{\text {DPPH }}$ is the concentration of DPPH solution expressed in $\mu \mathrm{g} / \mathrm{mL}$;

$\mathrm{E}$ is the extinction of the sample solution;

c.i. is the intercept of the curve;

c.s. is the slope of the curve.

The calculation equation of antioxidant activity (AA) is as follows: 


$$
A A \%=\frac{C_{i}-C_{f}}{C_{i}} * 100
$$

Where:

$\mathrm{C}_{\mathrm{i}}$ is the initial concentration of the standard solution;

$\mathrm{C}_{\mathrm{f}}$ is the final concentration of DPPH solution after it reacts with the antioxidant.

\section{Results and discussion}

\subsection{Volatile oil yield and aspect}

The yield of the extraction of volatile oil from Melissa officinalis L. dried herba was 0.17 $\mathrm{mL} / 100 \mathrm{~g}$. The extracted volatile oil has a yellowish-white color, has a characteristic, aromatic smell and a specific lemon aroma.

Abdellatif et al. investigated the yield of volatile oil extracted from Melissa officinalis L. dried leaves. They showed that the yield of extraction of the volatile oil from dried leaves of lemon balm was $0.34 \%(\mathrm{w} / \mathrm{w})$. They characterized the volatile oil as yellow-pale in color, with lemon smell [3]. Other authors showed that the yield of extraction of the volatile oil from fresh leaves of lemon balm was $0.5 \%(w / w)[6]$.

\subsection{Flavonoid content}

From the calibration curve, we obtained the following equation: $y=1.3 * x-0.11$, in which $y$ is the absorbance of the samples measured at $430 \mathrm{~nm}$ and $\mathrm{x}$ is the concentration of the samples. From this equation we found the concentration of the sample that we wanted to determine. Using the formula (2) we calculate the total flavonoid content which was equal to $0.965 \mathrm{~g} / 100 \mathrm{~g}$ weight of vegetal product.

Spiridon et al. showed that the total flavonoid content of an extract obtained from Melissa officinalis L. was $25.8 \pm 6.26 \mathrm{mg} / \mathrm{g}$ [13].

\subsection{Antioxidant activity}

The equation for the calibration curve was $y=0.0127 \mathrm{x}+0.0036$, where $\mathrm{y}$ is the extinction of DPPH solution determined at a wavelength of $515 \mathrm{~nm}$ and $\mathrm{x}$ is the concentration of the concentration $(\mu \mathrm{g} / \mathrm{mL})$ of DPPH solution. The percentage of antioxidant activity (AA \%) we obtained for methanolic extract of Melissa officinalis L. dried herba was 90,40\%.

Other researchers showed that water extract of Melissa officinalis L. leaves had a higher antioxidant capacity $(47.8 \%)$ than ethanol extract obtained from the same raw material $(7.4 \%)[2]$.

\section{Conclusion}

In conclusion, Melissa officinalis L. is a medicinal plant with a lot of applications and a potential source of compounds with antioxidant activity. Due to its variety of biological effects, the plant is used in traditional medicine for disease relief, but it is also used in pharmaceutical and food industries.

The yield of volatile oil extraction from dried aerial parts of lemon balm was low $(0.17$ $\mathrm{mL} / 100 \mathrm{~g}$ of vegetal product), so the high price of Melissa officinalis L. volatile oil is due to its low content in the plant. 
In this study, the total flavonoid content and antioxidant activity of some extracts of lemon balm were also analyzed. We showed that the extract obtained from aerial parts of Melissa officinalis L. possess antioxidant activity. This aspect is correlated to the flavonoid content which are well known for their antioxidant properties. This plant could be exploited by the pharmaceutical and food industries in order to improve human health.

\section{References}

1. S. Miraj, N. Azizi, S. Kiani, Scholar Research Library. Der Pharmacia Lettre 8, 229 (2016) https://www.scholarsresearchlibrary.com/abstract/a-review-of-chemicalcomponents-and-pharmacological-effects-ofrnmelissa-officinalis-1-2989.html

2. E. Koksal, E. Bursal, E. Dikici, F. Tozoglu, I. Gulcin, J. Med. Plant. Res. 5, 217 (2011) https://www.researchgate.net/publication/228481347_Antioxidant_activity_of_Melissa _officinalis_leaves

3. F. Abdellatif, H. Boudjella, A. Zitouni, A. Hassani, EXCLI Journal 13, 772 (2014) https://www.researchgate.net/publication/285733985_Chemical_composition_and_anti microbial_activity_of_the_essential_oil_from_leaves_of_Algerian_Melissa_officinalis _L

4. A. Shakeri, A. Sahebkar, B. Javadi, Journal of Ethnopharmacology 188, 204 (2016) https://doi.org/10.1016/j.jep.2016.05.010

5. R. A. Hussein, A. A. El-Anssary, Herbal Medicine, P.F. Builders Ed., IntechOpen: London, United Kingdom, 11-30 (2018) http://dx.doi.org/10.5772/intechopen.76139

6. A. Bounihi, G. Hajjaj, R. Alnamer, Y. Cherrah, A. Zellou, Advances in Pharmacological Sciences 2013, 101759 (2013) https://doi.org/10.1155/2013/101759

7. R. P. Pereira, A. A. Boligon, A. S. Appel, R. Fachinetto, C. S. Ceron, J. E. TanusSantos, M. L. Athayde, J. B. T. Rocha, Industrial Crops and Products 53, 34 (2014) https://doi.org/10.1016/j.indcrop.2013.12.007

8. S. Miraj, Rafieian-Kopaei, S. Kiani, Journal of Evidence-Based Complementary \& Alternative Medicine 22, 385 (2017) https://doi.org/10.1177/2156587216663433

9. J. Cases, A. Ibarra, N. Feuillere, M. Roller, S. G. Sukkar, Mediterr J Nutr Metab 4, 211 (2011)

10. Farmacopeea Română, Ed. X-a, Ed. Medicală, București, (1993)

11. M. K. Patel, A. Mishra, B. Jha, Front. Plant Sci. 7, 431 (2016) https://doi.org/10.3389/fpls.2016.00431

12. B. Tylkowski, I. Tsibranskaa, R. Kochanova, G. Peeva, M. Giamberini, Food Bioprod. Process. 89, 307 (2011) https://doi.org/10.1016/j.fbp.2010.11.003

13. I. Spiridon, S. Colceru, N. Anghel, C. A. Teaca, R. Bodirlau, A. Armatu, Natural Product Research 25, 657 (2011) http://dx.doi.org/10.1080/14786419.2010.521502 